Коннова Татьяна Анатольевна, учитель русского языка и литературы

ГБОУ ООШ с.Краснояриха муниципального района Челно-Вершинский

Самарской области

Тел.: 88465146356

e-mail: tatyana.pushenko@mail.ru

\title{
Дифференциация языковых единиц как методический приём при изучении орфографии (на примере изучения написания о-ё (е) после шипящих и ц в окончаниях и суффиксах существительных, прилагательных, суффиксах наречий)
}

Роль обобщений и дифференциации при изучении орфографии велика, поэтому в методической литературе проблеме обобщения и дифференциации уделяется большое место.

Так, А.И. Власенков отмечал в своих работах, что самостоятельная деятельность ученика с изучаемым материалом очень важна для повышения развивающей функции обучения. Поэтому содержанием учебных действий должны быть, прежде всего, обобщения.

Обобщение - это вывод, который учащиеся делают на основе анализа нескольких примеров, иллюстрирующих одно и то же лингвистическое явление. Большое значение имеют и такие «формы обобщения, как группировка и классификация (например, орфограмм в зависимости от их принадлежности к частям речи или по другим грамматическим признакам), упорядочение (например, расположение слов в зависимости от последовательности их образования или от усиления, или ослабления выражаемого им признака), продолжение перечня однородных в лингвистическом отношении элементов или, наоборот, исключение лишнего элемента, не соответствующего данному ряду. Высокую эффективность обнаруживают те обобщения, когда учащиеся подходят к языковым правилам через упражнения (трансформирование слов, словосочетаний, предложений) с последующим сопоставлением исходных и преобразованных форм. Выполнение заданий по контролю и самопроверке повышает действенность сделанных учащимися обобщений» [3].

Ученый отмечает, что если ученик назвал просто нужную орфограмму, это может оказаться результатом хорошей механической памяти, но если он выявил вид орфограммы и на этой основе установил принцип ее проверки, после чего применил правило, такой путь решения задачи свидетельствует об овладении обобщенным методом познавательной деятельности.

Орфографические ошибки нередко появляются в результате ошибочных обобщений. Причиной этого могут быть: ложные аналогии, которые приводят учащиеся между разными написаниями; применение ошибочных приемов распознания орфографических явлений, ошибочных обобщений орфографического и грамматического характера. В этих ошибках проявляется неумение учащихся применять орфографические правила.

Возникает вопрос, почему же учащиеся проводят эту ложную аналогию между различными орфографическими явлениями? А происходит это потому, что они не учитывают некоторых существенных особенностей слов при анализе на втором, выборочном этапе (этапе подведения орфограммы под правило):

1) характера морфемы, в частности, приставки;

2) способа образования слова;

3) к какой группе слов в пределах данной части речи относится слово (например, слово является полным причастием или кратким).

Ошибки появляются и на третьем, заключительном этапе (этапе определения существенных фонетических и грамматических признаков, на которые опираются орфографические правила). Учащиеся не учитывают того, что могут иметь слова-исключения. В результате школьники делают неправильные обобщения в виде орфографических правил и действуют при письме согласно этим ложным правилам. 
Неумение учащихся действовать по правилу проявляется и в том, что учащиеся применяют неверные приемы распознания орфографических явлений. Учащиеся, подчас пользуются одним каким-либо приемом, а не применяют совокупность их. Наблюдаются случаи, когда учащиеся неправильно пользуются тем или иным приемом.

Часто ошибки в словах с проверяемыми безударными гласными в корне объясняются тем, что учащиеся подбирают в качестве проверочных слов такие, в которых нужный корневой гласный находится в безударном положении. Обычно это происходит в том случае, если учащиеся не умеют правильно определять ударение или имеют недостаточный словарный запас. И, наконец, учащиеся применяют не тот прием определения написания, который необходим в данном конкретном случае. Неверные написания подчас являются результатом того, что учащиеся формулируют ложные правила и действуют при письме, руководствуясь этими правилами. Ложные правила могут возникать и по другим причинам: по аналогии с теми правилами, которые распространяются на родственные явления. Неверные написания появляются и в результате ошибочных обобщений грамматического характера (например, «с глаголами употребляется только частица НЕ» - этим объясняются ошибки в предложениях такого типа: «Куда не посмотрю, повсюду рать густая»).

Также ошибочные обобщения возникают нередко у учащихся и под влиянием обучения: некоторых особенностей формулировок правил, данных в учебнике, и упражнений, подобранных учителем. Например, вопрос о правописании непроизносимых согласных является сложным по ряду причин:

1) в настоящее время написание некоторых слов не определяется исходным корнем: блеснуть (хотя блестеть), склянка (стекло), лосниться (лоск);

2) корни с непроизносимыми согласными учащиеся смешивают с корнями, в которых эти согласные отсутствуют, типа: повестка

- отвесный, волостной - волосной, костный - косный, постлать - послать, частный - всечасный;

3) есть словарные слова, непроизносимый согласный в которых нельзя проверить, а нужно запомнить: чувство, лестница.

Так Н.Н. Алгазина отмечает то, что от учащихся нужно добиваться при ответе точной полной формулировки, которая объясняет конкретный случай, но в ней правило дано неполно, неточно.[1] Это может привести к ошибкам в других случаях.

Необходимо формулировать обобщающие правила. Вначале каждая орфограмма изучается отдельно, а затем они обобщаются. Тогда усвоение формулировки орфографического правила идет в процессе орфографического разбора. Это экономит время и способствует глубокому освоению орфографических правил.

Далее возникает вопрос: можно ли сделать так, чтобы учащиеся запоминали, с одной стороны, формулировку орфографического правила, а с другой стороны, правило применения этого правила, т.е. последовательность орфографического разбора?

Можно, если характер (содержание) умственных действий и последовательность их (алгоритм) намечается в самой формулировке правила. Мысль эта совсем не нова, её уже в свое время высказывали Н.С. Рождественский, Д.Н. Богоявленский, Л.П. Федоренко.

Процесс обобщения находится в тесной связи с процессом дифференциации. «Сравнение в обучении - распространенный дидактический прием и мыслительная операция, посредством которых устанавливаются черты сходства и различия между определенными предметами и явлениями» [4].

Прием сравнения содействует дифференциации изучаемых явлений и систематизации знаний учащихся.

В русском языке наблюдается много созвучных, но не одинаковых форм слов, которые обычно являются источником ошибок учащихся. Вовремя примененное сопоставление может помочь предупредить смешение таких форм и более осмысленно и глубоко усвоить их правописания. Сходные и различные написания отражают систему русского правописания. Многие исследователи отмечали это (Н.С. Рождественский, А.Г.Сергиевский и др.) также пользу метода сопоставления в обучении навыкам правописания. 
Метод сравнения как один из эффективных приемов обучения получил широкое распространение в школе. Внимание к нему объясняется настойчивыми поисками путей и средств повышения качества знаний и навыков учащихся, в процессе обучения и развития у детей самостоятельности при изучении фактов и явлений.

Сравнение - мыслительная операция (установление отношений сходства и различия между предметами и явлениями окружающего мира) совершается, как правило, в процессе познания и непроизвольно. Мыслительная операция сравнения лежит в основе методического приема сравнения.

В занятиях по орфографии имеется возможность широко использовать разнообразные виды сопоставления:

1. По характеру умственной работы различаются основные виды сопоставления: установление сходства (аналогии) и различия.

2. По объему сравниваемых объектов изучения используется сопоставление одиночных написаний (составляющих пары слов) и групп написаний.

3. По характеру сравниваемых объектов применяются разновидности сопоставления:

1) сопоставление правил правописания;

2) сопоставление сходных и различных написаний;

3) установление сходства и различия между написанием и произношением слов;

4) сопоставление лексических значений созвучных слов;

5) сравнение по сходству и различию морфологических частей слов;

6) сравнение грамматических категорий и их форм.

Сопоставления применяются в различных случаях: при изучении нового материала и в процессе повторения пройденного, при выполнении тренировочных упражнений, при проверке знаний и навыков учащихся и в работе над ошибками.

Внешне сходные слова, довольно распространенные в русском языке, нередко служат источником смешения грамматических форм. М.В. Ушаков отмечает в своей работе: «Наиболее трудными по своему правописанию являются те морфологические части слова, которые совпадают по своему произношению и, следовательно, могут быть смешаны при письме» [5]. При изучении правописания школьниками бывают, посильны главным образом несложные, более доступные для них виды сопоставления, которые имеют весьма близкую связь, ярко выраженное сходство или различие. При повторении пройденного материала имеются наибольшие возможности в применении разных видов сопоставления, охватывающих большой круг вопросов.

Сравнение даёт возможность обосновать, проверить правописание таких орфограмм, которые не относятся к числу проверяемых. Сопоставление активизирует процесс обучения, мобилизует внимание школьников, вызывает у них интерес к занятиям по орфографии, содействует лучшему восприятию правил.

Под методическим приемом сравнения мы понимаем следующие действия учителя и учащихся:

1. Выбор учителем или учеником сравнения (что с чем сравнивать) и определения цели сравнения (сходства или различия устанавливать при сравнении).

2. Вычленения признаков для сравнения объектов.

3. Сравнение объектов, то есть установления сходства или различия.

4. Обобщение наблюдений.

Обучение с использованием сравнения предполагает активную аналитико-синтетическую деятельность учащихся и способствует развитию всех мыслительных операций: анализа, синтеза, сравнения, обобщения, классификации и др. Сначала выделяются признаки грамматических явлений (объектов сравнения). Это анализ. Затем объекты сравниваются по вычлененным признакам (сравнение). При наличии сходства или тождества признаков проводится обобщение или классификация.

Сравнение - это эффективный прием еще и потому, что знания учащихся становятся более прочными, устойчивыми, действенными. Ученики более свободно оперируют своими знаниями в практике устной и письменной речи. 
Занятия, проводимые с широким использованием метода сопоставления, дали весьма благоприятный результат. При систематическом сравнении и обобщении учащиеся устанавливают в языке определенные закономерности и начинают воспринимать учебный предмет не как ряд разрозненных сведений, фактов, а как определенную систему, науку.

Орфографические ошибки нередко появляются в результате ошибочных обобщений и сравнений грамматического и орфографического характера. Так, при изучении написания оё (е) после шипящих и ц в окончаниях и суффиксах существительных, прилагательных, суффиксах наречий необходимо предусмотреть смешение с другими правилами правописания:

1. Орфограммы, связанные с правописанием о-ё (е) после шипящих в именных частях речи, учащиеся смешивают с правилом «Жи, ии пиши с буквой $u »$.

В суффиксах существительных:

букашек, горошек, дорожек, крошек, ложечку, подушенька;

В суффиксах прилагательных: плюшевый;

В окончаниях существительных: вылгрышем, под душем, ландышем, маршем, мякишем, репортажем, экипажем;

В окончаниях прилагательных: свежей.

2. Орфограммы, связанные с правописанием о-ё (е) после шипящих в именных частях речи, учащиеся смешивают с правилом «Ча, ща пиши с буквой $a »$ в следующих словах:

дачей, кручей, кучей, тучей; гущей, кущей, пущей, чащей.

3. Орфограммы, связанные с правописанием о-ё (е) после шипящих в именных частях речи, учащиеся смешивают с правилами написания суффиксов -ек-, -ик- и -чик-, -щик-. Нарушая правила правописания $o$ и $e$ в суффиксах существительных после шипящих, учащиеся пишут вместо буквы $e$ букву $u$ («овражик», «орешик»). Это наблюдается в следующих словах:

букашек, замочек, колючек, кружочек, кулёчек, кусочек, мечочек, ночек, сыночек.

4. Орфограммы, связанные с правописанием о-ё (е) после шипящих в именных частях речи, учащиеся смешивают с правилом правописания «и-bl после и̧» в окончаниях существительных и прилагательных («ситщзивый» «курищий»)

Имена существительные:

возницей, границей, девицей, жужелицей, зарницей, искусницей, ключницей, красавицей, кудесницей, куницей, курицей, лестницей, лисицей, лучницей мастерицей, медведицей, мученицей, палицей, птицей, синицей, спицей, улицей, ученицей, царицей.

Имена прилагательные:

глянцевый, зайцевьій, квариевый, кольцевой, лицевой, марганцевьй, пальцевой, ситиевый, ториевой, флецевый.

5. Учащиеся смешивают написание суффиксов отглагольных

существительных и прилагательных с правописанием отглагольных существительных и прилагательных. Это наблюдается в следующих словах:

ночёвка, размежёвка, сгущёнка, трещотка, трущоба, тушёнка.

6. Учащиеся смешивают написание суффиксов и окончаний в именах собственных, подчиняющихся правилу, с традиционными написаниями.

\begin{tabular}{|c|c|c|}
\hline В окончаниях & $\begin{array}{c}\text { Кузьмичом } \\
\text { Лукичом }\end{array}$ & Ильичём \\
\hline & Пугачов & Пугачёв \\
& Калачов & Калачёв \\
В суффиксах & Хрущов & Хрушёв \\
& Ткачов & Черньишёв \\
\hline
\end{tabular}

Из всего вышесказанного следует вывод: при изучении орфограмм (в нашем случае - это правописание о-ё (е) после шипящих и ц в окончаниях и суффиксах существительных, прилагательных, суффиксах наречий) важно учитывать условия, препятствующие, 
образованию нужных ассоциаций. Необходимо осуществлять учет вариантов орфограмм, производить обобщение материала и раннюю дифференциацию смешиваемых языковых явлений.

\section{Список используемой литературы:}

1. Алгазина Н.Н. Анализ орфографических ошибок и пути их преодоления. М., 1965.

2. Алгазина Н.Н. Дидактический материал по орфографии с компьютерной поддержкой. Пособие для учащихся 5-7 классов. М., 1996.

3. Власенков А.И. Развивающее обучение русскому языку. М., 1983, с.29.

4. Педагогический словарь, Т.2, М., изд. АПН РСФСР, 1960, с. 420.

5. Ушаков М.В. Методика правописания. М., 1947. 